\title{
Treatment of thin endometrium with autologous platelet-rich plasma: a pilot study
}

\author{
Shahrzad Zadehmodarres ${ }^{1}$, Saghar Salehpour ${ }^{1}$, Nasrin Saharkhiz ${ }^{1}$, Leila Nazari ${ }^{1}$ \\ ${ }^{1}$ Department of Obstetrics and Gynecology, Preventive Gynecology Research Center, Shahid Beheshti Universi- \\ ty of Medical Sciences, Tehran, Iran
}

\begin{abstract}
Endometrium is one of the main factors in pregnancy. During assisted reproductive technology (ART) treatments, some cycles are cancelled due to inadequate endometrial growth. This study was conducted to evaluate the effectiveness of platelet-rich plasma (PRP) in the treatment of thin endometrium. Ten patients with history of inadequate endometrial growth in frozen-thawed embryo transfer (FET) cycles were recruited into the study. Intrauterine infusion of PRP was performed. Endometrial thickness was assessed. Chemical and clinical pregnancies were reported. In all patients, endometrial thickness increased after PRP and embryo transfer was done in all of them. Five patients were pregnant. According to this study, it seems that PRP was effective for endometrial growth in patient with thin endometrium.
\end{abstract}

Keywords: platelet-rich plasma, thin endometrium, frozen-thawed, embryo transfer

\section{INTRODUCTION}

Endometrium is one of the main factors in implantation and pregnancy. Pregnancy rate is increased with growing endometrial thickness. In several studies, the minimum endometrium thickness for embryo transfer was reported to be $7 \mathrm{~mm}$ (El-Toukhy et al., 2008; Richter et al., 2007). Several methods are performed for endometrial preparation in frozen-thawed embryo transfer (FET) cycles, and there is little consensus on the most effective route. Some FET cycles are cancelled due to thin endometrium despite routine treatment, and there is no established protocol for this condition. Extended estrogen treatment and adjuvant therapy, such as low dose Aspirin, vaginal Sildenafil, Pentoxifylline and intrauterine perfusion with granulocytecolony stimulating factor (G-CSF) have been used for thin endometrium, but there isn't any proved evidence in this treatment (Barad et al., 2014; Chang et al., 2015; Eftekhar et al., 2014; Gleicher et al., 2013; Groenewoud et al., 2013; Lebovitz \& Orvieto, 2014; Xu et al., 2015).

Intrauterine infusion of platelet-rich plasma (PRP) is a new approach that has been suggested for the treatment of thin endometrium (Chang et al., 2015). PRP is blood plasma prepared from fresh whole blood that has been enriched with platelets. It is collected from peripheral veins and contains several growth factors such as vascular endothelial growth factor (VEGF), epidermal growth factor (EGF), platelet derived growth factor (PDGF), transforming growth factor (TGF) and other cytokines that stimulate proliferation and growth. Recently, PRP has been used in several medical conditions in ophthalmology, orthopedics, surgery and wound healing but it's efficacy in endometrial growth has not been fully elucidated. The aim of this study was to evaluate the effectiveness of intrauterine infusion of PRP in the treatment of thin endometrium in FET cycles
(El-Anwar et al., 2016; Lee et al., 2016; Maria-Angeliki et al., 2015; Picard et al., 2015; Ronci et al., 2015; Rossi et al., 2016; Sadabad et al., 2016).

\section{CASES DESCRIPTION}

Ten patients who had a history of cancelled cycles due to inadequate endometrial growth (less than $7 \mathrm{~mm}$ ) in the past FET cycles despite standard treatments, were recruited into the study performed in the IVF center, Taleghani Hospital, Tehran, Iran from September 2015 to May 2016. All patients signed an informed written consent. The study was approved by the ethical committee of the Shahid Beheshti University of Medical Sciences (SBMU) (IR.SBMU.SM.REC.1394.92). Patients' characteristics and FET outcome data are summarized on Table 1.

Hysteroscopic examination was performed before the cycle, if it had not been done previously. Hormone replacement therapy (HRT) was performed for endometrial preparation in all participant: estradiol valerate (Progynova; Bayer Schering Pharma, France) $6 \mathrm{mg} / \mathrm{d}$ was started on the $2^{\text {nd }}$ or $3^{\text {rd }}$ day of the mensural cycle and it was increased to $8 \mathrm{mg} / \mathrm{d}$ on day $9-10$ because of inadequate endometrial growth $(<7 \mathrm{~mm})$. PRP was performed on day $11-12$ in all the patients due to thin endometrium and it was repeated on day 13-14. During the cycle, whenever the endometrial thickness was more than $7 \mathrm{~mm}$, suppository progesterone (Cyclogest; Actavis, UK limited, England) 400 mg twice-aday was started and embryo transfer (ET) was carried out per embryonic stage. Estradiol valerate and progesterone supplementation were continued for 2 weeks after ET and if the serum $\beta$ HCG was positive, hormone supplementations were continued until 12 weeks of gestation.

Transvaginal ultrasound was performed by an expert gynecologist with a fellowship in infertility by one machine. Endometrial thickness was measured at the thickest part in the longitudinal axis of the uterus.

PRP was prepared from autologous blood using a two-step centrifuge process. On the $9^{\text {th }}$ or $10^{\text {th }}$ day of the mensural cycle, $17.5 \mathrm{ml}$ of peripheral venous blood was drawn in the syringe that contained $2.5 \mathrm{ml}$ of Acid Citrate A Anticoagulant solution (ACD-A) (Arya Mabna Tashkhis, Iran) and centrifuged immediately at $1200 \mathrm{rpm}$ for $12 \mathrm{~min}$ to separate the red blood cells. The plasma was centrifuged again at $3300 \mathrm{rpm}$ for $7 \mathrm{~min}$ to obtain the PRP. Then, 0.5 $\mathrm{ml}$ of PRP was infused into the uterine cavity with the IUI catheter (Takwin, Iran).

The primary outcome was endometrial expansion and the secondary outcomes were chemical and clinical pregnancies, determined by positive serum BHCG, 2 weeks after ET and the presence of fetal hear beat in the transvaginal ultrasound 5 weeks after ET.

\section{RESULTS}

A total of 10 patients with a history of FET cancellation due to thin endometrium were recruited into the study. 


\begin{tabular}{|c|c|c|c|c|c|c|}
\hline Patient & Age & Diagnosis & $\begin{array}{l}\text { Endometrial* } \\
\text { thickness }(\mathrm{mm})\end{array}$ & $\begin{array}{c}\text { Embryos } \\
\text { transferred } \\
\text { (no.) }\end{array}$ & $\begin{array}{l}\text { Chemical } \\
\text { pregnancy }\end{array}$ & $\begin{array}{l}\text { Clinical } \\
\text { pregnancy }\end{array}$ \\
\hline 1 & 30 & Tubal factor & $4 / 6.1 / 7.2$ & 2 & No & No \\
\hline 2 & 34 & Male Factor & $5 / 6.8 / 7.5$ & 3 & Yes & Yes \\
\hline 3 & 33 & $\begin{array}{l}\text { Anovulation } \\
+ \text { Male factor }\end{array}$ & $5 / 6 / 7.1$ & 2 & No & No \\
\hline 4 & 30 & $\begin{array}{l}\text { Endometriosis } \\
+ \text { Male factor }\end{array}$ & $4.5 / 5.8 / 7.5$ & 2 & & \\
\hline 5 & 39 & DOR** & $4.6 / 5.2 / 7.2$ & 2 & Yes & No*** \\
\hline 6 & 35 & DOR** & $4.5 / 5.5 / 7$ & 3 & No & No \\
\hline 7 & 31 & Male factor & $6 / 6.3 / 7.4$ & 2 & Yes & Yes \\
\hline 8 & 39 & $\begin{array}{c}\text { DOR** } \\
+ \text { Male factor }\end{array}$ & $4.3 / 5.2 / 7.1$ & 2 & Yes & Yes \\
\hline 9 & 35 & $\begin{array}{l}\text { Anovulation } \\
+ \text { Male factor }\end{array}$ & $4.8 / 5.2 / 7.2$ & 2 & No & No \\
\hline 10 & 37 & DOR & $5.3 / 6.1 / 7.3$ & 2 & Yes & Yes \\
\hline
\end{tabular}

*Endometrial thickness $(\mathrm{mm})$ : Before PRP/48 $\mathrm{h}$ after first PRP/48h after second PRP

$* *$ DOR: Diminished ovarian reserve

$* * *$ Miscarriage

Uterine cavity abnormalities were not detected before starting the cycle. Four participants had a past of therapeutic resectoscopic hysteroscopy due to Asherman's syndrome and myoma. All the participants needed PRP in the treatment cycles due to inadequate endometrium growth. Endometrial thickness increased at $48 \mathrm{~h}$ after the first PRP and reached more than $7 \mathrm{~mm}$ after the second PRP in all patients. Embryo transfer was then carried out for all of them. Five patients were pregnant and in four of them the pregnancy progressed normally.

\section{DISCUSSION}

PRP is autologous blood plasma that has been enriched with platelets at about 4-5 times more than the circulating blood. PRP can stimulate proliferation and regeneration with a large amount of growth factors and cytokines, including PDGF, TGF, VGEF, EGF, fibroblast growth factor (FGF), insulin-like growth factor I, II (IGF I, II), interleukin 8 (IL8 ) and connective tissue growth factor (CTGF). Currently, PRP infusion is being increasingly used in several fields in medicine such as nerve injury, osteoarthritis, chronic tendinitis, bone repair and regeneration, cardiac muscles, alopecia, plastic surgery and oral surgery, but there is limited experience in gynecology and obstetrics (Alcaraz et al., 2015; Borrione et al., 2010; Patel et al., 2016; Yu et al., 2011).

For the first time, Chang reported the efficacy of intrauterine infusion of PRP for endometrial growth in women with thin endometrium. In that trial, PRP was infused in 5 women with inadequate endometrium who had poor response to conventional therapy during the FET cycle. The proper response to treatment was reported in all of them, and normal pregnancy was reported in 4 women (Chang et al., 2015).

Adequate endometrial thickness is a main factor for implantation and pregnancy. Women with persistent thin endometrium often do not undergo embryo transfer. Several methods have been described for endometrial preparation but there is not any definitive method yet. In recent years, intrauterine infusion of G-CSF has been studied but inconsistent results have been reported. Some researchers reported that G-CSF favors endometrial growth and pregnancy. G-CSF is a cytokine that stimulates neutrophilic granulocyte differentiation and proliferation, it may induce endometrium proliferation and growth, thus improve pregnancy outcome. According to this hypothesis, local infusion of PRP that contains several growth factors and cytokines may improve endometrial growth and receptivity. PRP is collected from autologous blood sample, so in comparison to G-CSF, PRP is more accessible and affordable (Gleicher et al., 2011; Lucena \& Moreno-Ortiz, 2013).

The results of our pilot study revealed the efficacy of PRP on endometrial growth. Adequate endometrial growth was found in all the participants after two PRP infusions in all patients who had a history of cycle cancellation due to thin endometrium. At the present, there is limited evidence in this regard. Hence, we suggest further clinical trials in this context. PRP is a safe procedure, with minimal risks of transmission of infectious disease and immunological reactions since it is made from autologous blood samples.

\section{CONCLUSION}

According to this study, it seems that PRP was effective for endometrial growth in patients with thin endometrium.
Abbreviation
ART Assisted reproductive technology
PRP Platelet-rich plasma
FET Frozen-thawed embryo transfer
G-CSF Granulocyte-colony stimulating factor
ET embryo transfer

Acknowledgement: This present paper was financially supported by the Research Department of the School of Medicine Shahid Beheshti University of Medical Sciences (Grant no 6776).

\section{CONFLICT OF INTERESTS}

No conflict of interests has been declared.

\section{Corresponding author:}

Leila Nazari

Department of Obstetrics and Gynecology 
IVF center, Taleghani Hospital, Tehran, Iran.

E-mail: nazari@sbmu.ac.ir

\section{REFERENCES}

Alcaraz J, Oliver A, Sánchez JM. Platelet-Rich Plasma in a Patient with Cerebral Palsy. Am J Case Rep. 2015;16:469-72. PMID: 26185982 DOI: http://dx.doi.org/10.12659/AJCR.893805

Barad DH, Yu Y, Kushnir VA, Shohat-Tal A, Lazzaroni $\mathrm{E}$, Lee $\mathrm{HJ}$, Gleicher N. A randomized clinical trial of endometrial perfusion with granulocyte colony-stimulating factor in in vitro fertilization cycles: impact on endometrial thickness and clinical pregnancy rates. Fertil Steril. 2014;101:710-5. PMID: 24424357 DOI: http://dx.doi.org/10.1016/j.fertnstert.2013.12.016

Borrione P, Gianfrancesco AD, Pereira MT, Pigozzi F. Platelet-rich plasma in muscle healing. Am J Phys Med Rehabil. 2010;89:854-61. PMID: 20855985 DOI: http://dx.doi.org/10.1097/PHM.0b013e3181f1c1c7

Chang Y, Li J, Chen Y, Wei L, Yang X, Shi Y, Liang X. Autologous platelet-rich plasma promotes endometrial growth and improves pregnancy outcome during in vitro fertilization. Int J Clin Exp Med. 2015;8:1286-90. PMID: 25785127

Eftekhar M, Sayadi M, Arabjahvani F. Transvaginal perfusion of G-CSF for infertile women with thin endometrium in frozen ET program: A non-randomized clinical trial. Iran J Reprod Med. 2014;12:661-6. PMID: 25469123

El-Anwar MW, Nofal AA, Khalifa M, Quriba AS. Use of autologous platelet-rich plasma in complete cleft palate repair. Laryngoscope. 2016;126:1524-8. PMID: 27075516 DOI: http://dx.doi.org/10.1002/lary.25868

El-Toukhy T, Coomarasamy A, Khairy M, Sunkara K, Seed $P$, Khalaf $Y$, Braude $P$. The relationship between endometrial thickness and outcome of medicated frozen embryo replacement cycles. Fertil Steril. 2008;89:832-9. PMID: 17681313 DOI: http://dx.doi.org/10.1016/j.fertnstert.2007.04.031

Gleicher N, Vidali A, Barad DH. Successful treatment of unresponsive thin endometrium. Fertil Steril. 2011;95:2123.e13-7. PMID: 21324451 DOI: https://doi.org/10.1016/j.fertnstert.2011.01.143

Gleicher N, Kim A, Michaeli T, Lee HJ, Shohat-Tal A, Lazzaroni E, Barad DH. A pilot cohort study of granulocyte colony-stimulating factor in the treatment of unresponsive thin endometrium resistant to standard therapies. Hum Reprod. 2013;28:172-7. PMID: 23081869 DOI: http://dx.doi.org/10.1093/humrep/des370

Groenewoud ER, Cantineau AE, Kollen BJ, Macklon NS, Cohlen BJ. What is the optimal means of preparing the endometrium in frozen-thawed embryo transfer cycles? A systematic review and meta-analysis. Hum Reprod Update. 2013;19:458-70. PMID: 23820515 DOI: http://dx.doi.org/10.1093/humupd/dmt030

Lebovitz O, Orvieto R. Treating patients with "thin" endometrium - an ongoing challenge. Gynecol Endocrinol. 2014;30:409-14. PMID: 24693854 DOI: http://dx.doi.org/10.3109/09513590.2014.906571
Lee JH, Kim MJ, Ha SW, Kim HK. Autologous Platelet-rich Plasma Eye Drops in the Treatment of Recurrent Corneal Erosions. Korean J Ophthalmol. 2016;30:101-7. PMID: 27051257 DOI: http://dx.doi.org/10.3341/kjo.2016.30.2.101

Lucena E, Moreno-Ortiz H. Granulocyte colony-stimulating factor (G-CSF): a mediator in endometrial receptivity for a patient with polycystic ovary (PCO) undergoing in vitro maturation (IVM). BMJ Case Rep. 2013;pii: bcr2012008115. PMID: 23605819 DOI: https://doi.org/10.1136/bcr-2012-008115

Maria-Angeliki G, Alexandros-Efstratios K, Dimitris R, Konstantinos K. Platelet-rich Plasma as a Potential Treatment for Noncicatricial Alopecias. Int J Trichology. 2015;7:54-63. PMID: 26180449 DOI: http://dx.doi.org/10.4103/0974-7753.160098

Patel AN, Selzman CH, Kumpati GS, McKellar SH, Bull DA. Evaluation of autologous platelet rich plasma for cardiac surgery: outcome analysis of 2000 patients. J Cardiothorac Surg. 2016;11:62. PMID: 27068030 DOI: http://dx.doi.org/10.1186/s13019-016-0452-9

Picard F, Hersant B, Bosc R, Meningaud JP. The growing evidence for the use of platelet-rich plasma on diabetic chronic wounds: A review and a proposal for a new standard care. Wound Repair Regen. 2015;23:638-43. PMID: 26019054 DOI: http://dx.doi.org/10.1111/wrr.12317

Richter KS, Bugge KR, Bromer JG, Levy MJ. Relationship between endometrial thickness and embryo implantation, based on 1,294 cycles of in vitro fertilization with transfer of two blastocyst-stage embryos. Fertil Steril. 2007;87:53-9. PMID: 17081537 DOI: http://dx.doi.org/10.1016/j.fertnstert.2006.05.064

Ronci C, Ferraro AS, Lanti A, Missiroli F, Sinopoli S, Del Proposto G, Cipriani C, De Felici C, Ricci F, Ciotti M, Cudillo L, Arcese W, Adorno G. Platelet-rich plasma as treatment for persistent ocular epithelial defects. Transfus Apher Sci. 2015;52:300-4. PMID: 25728718 DOI: http://dx.doi.org/10.1016/j.transci.2014.12.027

Rossi LA, Molina Rómoli AR, Bertona Altieri BA, Burgos Flor JA, Scordo WE, Elizondo CM. Does platelet-rich plasma decrease time to return to sports in acute muscle tear? A randomized controlled trial. Knee Surg Sports Traumatol Arthrosc. 2016. [Epub ahead of print] PMID: 27085364 DOI: http://dx.doi.org/10.1007/s00167-016-4129-7

Sadabad HN, Behzadifar M, Arasteh F, Behzadifar M, Dehghan HR. Efficacy of Platelet-Rich Plasma versus Hyaluronic Acid for treatment of Knee Osteoarthritis: A systematic review and meta-analysis. Electron Physician. 2016;8:2115-22. PMID: 27123220 DOI: http://dx.doi.org/10.19082/2115

Xu B, Zhang Q, Hao J, Xu D, Li Y. Two protocols to treat thin endometrium with granulocyte colony-stimulating factor during frozen embryo transfer cycles. Reprod Biomed Online. 2015;30:349-58. PMID: 25682303 DOI: http://dx.doi.org/10.1016/j.rbmo.2014.12.006

Yu W, Wang J, Yin J. Platelet-rich plasma: a promising product for treatment of peripheral nerve regeneration after nerve injury. Int J Neurosci. 2011;121:176-80. PMID: 21244302 DOI: http://dx.doi.org/10.3109/00207454.2010.544432 